\title{
Efficacy of combined treatment with vacuum sealing drainage and recombinant human epidermal growth factor for refractory wounds in the extremities and its effect on serum levels of IL-6, TNF- $\alpha$ and IL-2
}

\author{
LEI TAN ${ }^{1 *}$, ZHONGYU $\mathrm{HOU}^{2 *}$ and YANZHI GAO ${ }^{3}$ \\ ${ }^{1}$ Traumatology Ward I, Zhangqiu Hospital of Chinese Medicine, Zhangqiu, Shandong 250200; ${ }^{2}$ Traumatology Ward II, \\ Laiwu Iron and Steel Group Co. Ltd. Hospital, Laiwu, Shandong 271126; ${ }^{3}$ Department of Emergency, \\ The Central Hospital of Shengli Oilfield, Dongying, Shandong 257034, P.R. China
}

Received June 21, 2017; Accepted October 6, 2017

DOI: $10.3892 /$ etm.2017.5360

\begin{abstract}
The objective of this study was to investigate the efficacy of combined treatment with vacuum sealing drainage (VSD) and recombinant human epidermal growth factor (rhEGF) for refractory wounds in the extremities, and its effect on serum levels of interleukin-6 (IL-6), tumor necrosis factor- $\alpha(\mathrm{TNF}-\alpha)$, and IL-2. Ninety-eight patients with refractory wounds in the extremities were recruited and randomly divided into the combined treatment group (underwent VSD and rhEGF treatment) and control group (underwent VSD only) with 49 cases each. Formation of granulation tissue on the wound surface was assessed and scored. The wound healing rate was calculated after 1 week of treatment, and the time of complete healing was recorded. Serum levels of IL-6, IL-2, and TNF- $\alpha$ were measured using enzyme-linked immunosorbent assay. After 1 week of treatment, granulation tissue formation on wound surfaces was significantly improved $(\mathrm{p}<0.05)$ compared with that before treatment in both groups. Moreover, granulation tissue formation on wound surfaces was superior in the combined treatment group than in the control group $(\mathrm{p}<0.05)$. The wound healing rate was $63.50 \pm 4.75 \%$ in the combined treatment group and $31.79 \pm 3.52 \%$ in the control group, and the difference was statistically significant $(\mathrm{p}<0.05)$. The time of complete healing was $15.11 \pm 2.24$ days in the combined treatment group and $19.63 \pm 2.76$ days in the control
\end{abstract}

Correspondence to: Dr Yanzhi Gao, Department of Emergency, The Central Hospital of Shengli Oilfield, 31 Jinan Road, Dongying, Shandong 257034, P.R. China

E-mail: gyp7pv@163.com

*Contributed equally

Key words: vacuum sealing drainage, recombinant human epidermal growth factor, hand and foot surgery, refractory wound, inflammatory factor group, and the difference was statistically significant $(\mathrm{p}<0.05)$. The serum levels of IL-6, IL-2, and TNF- $\alpha$, in the two groups were significantly lower than those before treatment $(\mathrm{p}<0.05)$. Moreover, the levels in the combined treatment group were significantly lower than those in the control group $(\mathrm{p}<0.05)$. In conclusion, combined treatment with VSD and rhEGF reduced inflammation and shortened the time of complete healing of refractory wounds in the extremities. Measurement of the levels of related inflammatory factors provided a reference for the prognosis of refractory wounds.

\section{Introduction}

Refractory wounds because of trauma, burn/scald, vascular ulcer on the hand or foot, and the diabetic foot pose a challenge in clinical hand and foot surgery (1). Clinical manifestations of refractory wounds include local pain and discomfort, and secondary infection of surrounding skin resulting in skin irritation, congestion, exudation, erosion, and ulcers. The condition poses a substantial challenge for clinical intervention, which causes great psychological stress to patients and medical personnel. Patients can lose confidence in both their ability to be cured and their future quality of life (2). Vacuum sealing drainage (VSD) is a therapeutic technique which involves a vacuum dressing to promote healing of acute or chronic wounds. It involves application of wound dressing made of polyethylene alcohol hydrated alginate foam with drainage tubes to fill or cover the wound surface of patients with skin or soft tissue defects. Next, a biological semipermeable membrane film is applied to seal the wound surface with the dressing on to form a closed microenvironment. When the drainage tubes are connected with a vacuum source, a controlled negative pressure is established, which draws out fluid from the wound and increases blood flow to the affected area (3). The established negative pressure can also promote protein synthesis on the wound surface to accelerate granulation tissue growth, and eventually promotes healing of the wound. In addition, the closed microenvironment formed through sealing with the biological semipermeable membrane 
prevents the wound surface from infection from contact with the outside environment. Drainage tubes with multiple sideopenings inserted in the wound dressing aspirate the necrotic tissue and exudate in a timely manner, thus reducing the need for antibiotic use (4). Epidermal growth factor (EGF) is a multifunctional cellular growth factor that acts by binding to the epidermal growth factor receptor (EGFR) on the cell surface (5). EGFR is expressed on the cell membrane of epidermal cells, fibroblasts, endothelial cells, and smooth muscle cells. Furthermore, the highest levels of EGFR expression are found in epidermal cells (6). Binding of EGF to EGFR with high affinity stimulates the receptor's intrinsic protein tyrosine kinase activity, which subsequently stimulates a signal transduction cascade leading to multiple biochemical changes in the cell. This includes elevation of calcium level, increase of glycolysis and protein synthesis, and upregulation of EGFR expression. Binding of EGF to EGFR eventually promotes DNA synthesis and cell proliferation, resulting in accelerated cell metabolism $(7,8)$. A solution containing recombinant human epidermal growth factor (rhEGF) for external use can be applied to burn wounds (including shallow and deep second degree burn wounds), residual wounds, various types of chronic ulcer wounds (including vascular, radiation, and diabetic ulcer), and fresh wounds on skin donor sites. In the present study, we evaluated the efficacy of VSD combined with rhEGF treatment for refractory traumatic wounds of the extremities, and its effect on the serum levels of interleukin- 6 (IL-6), TNF- $\alpha$, and IL-2.

\section{Patients and methods}

Patients. Ninety-eight patients with refractory traumatic wounds in the extremities who were admitted to Shengli Hospital from January 2015 to December 2016 were recruited.

Inclusion criteria. i) Patients with chronic refractory wounds for over 1 month caused by all forms of trauma, continuous deteriorating wounds, or wounds with a diameter $>3 \mathrm{~cm}$; ii) patients not previously treated with VSD; iii) patients with no improvement after 7 days of drug treatment for a normal wound; and iv) patients with contaminated wounds.

Exclusion criteria. i) Patients with combined severe heart, brain, liver, kidney, or hematopoietic diseases; ii) patients with malignant tumors derived from skin or soft tissue; iii) patients with immune diseases who were exposed to high doses of immunosuppressive agents, steroid hormones, or chemotherapy drugs for extended periods of time; iv) patients with severe malnutrition or moderate to severe anemia; and v) patients with active bleeding on the wound.

Causes for complete loss to follow-up and remedial measure. There were two causes for complete loss to follow-up. Either patients chose to withdraw from the trial or they were transferred to other hospitals for further treatment. In case of patient withdrawal, new patients were recruited according to the inclusion and exclusion criteria.

Medical ethics. Patients or family members signed a consent form to participate in the study. Safety and welfare of the patients were protected according to relevant clinical guidelines. Privacy of the patients was protected by keeping their medical records confidential.

Clinical trial design: Double-blind. Researchers were divided into four groups. The first group was responsible for screening and grouping of the patients, the second group for patient treatment, the third group for collecting clinical data, and the fourth group for statistical analysis and manuscript writing. Assignment of patients was strictly confidential to them. Moreover, the detailed procedures performed by the four groups of researchers were kept confidential from each other.

Grouping of patients. In this study, a total of 70 males and 28 females, aged 36-78 years, with mean age of 58.5 \pm 9.4 years were enrolled. Regarding cause of wounds, there were 39 cases of injury from car accident, 25 cases of injury from falling object, nine cases of injury from electric shock, 10 cases of varicose ulcer, and 15 cases of diabetic foot. Regarding wound location, there were 32 cases with wounds on the heel, eight cases on the top of the foot, 18 cases on the ankle, 17 cases on the back of the hand, eight cases on the palm, and 15 cases on the calf. Regarding wound condition, there were 59 cases with slight wound contamination or minimal purulent exudation, and 39 cases with severe infection or obvious pus with foul odor. The 98 patients were randomly divided into the combined treatment group (underwent combined treatment with VSD and rhEGF) and control group (underwent VSD only), with 49 cases each. There were 36 males and 13 females with mean age of $59.21 \pm 10.23$ years in the combined treatment group, and

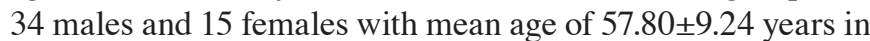
the control group. The medical Ethics Committee of Shengli Hospital reviewed and approved this study. Patients or their families signed the informed consent.

Methods. VSD was performed on all patients in both groups. After successful local anesthesia with $1 \%$ lidocaine, wounds were routinely rinsed three times with benzalkonium bromide, povidone iodine, $\mathrm{H}_{2} \mathrm{O}_{2}$, and $0.5 \%$ iodophor solution, followed by rinsing with saline to clean the wounds and surrounding areas to remove the necrotic stratum corneum. For patients in the combined treatment group, a solution of rhEGF was uniformly sprayed on the surface of wounds after the surrounding skin was dry, followed by incubation for at least $90 \mathrm{sec}$. For patients in the control group, no rhEGF spray was applied after saline rinse and air-dry. Specific application of the VSD dressing (Shandong Chuangkang Biotechnology Co., Ltd.) depended on the shape and size of the wound. If the wound area was large, it was covered by the dressing in an imbricate mode, and the VSD dressing was made to completely cover the wound and $2-3 \mathrm{~cm}$ of surrounding skin. If the wound was deep, the dressing was filled completely to the bottom of the cavity, leaving no dead space. The biologically permeable film was applied above the dressing to cover an area of 4-5 cm wider than the wound surface. After a double check of tight sealing, the drainage tube was connected to a negative pressure drainage device (Shandong Weigao New Life Medical Devices Co., Ltd., Weihai, China), and a negative pressure of $80-125 \mathrm{mmHg}$ was set and maintained. The wound dressing was replaced every 5 days. During the 
Table I. General data of patients in the two groups.

\begin{tabular}{|c|c|c|c|c|}
\hline Parameters & $\begin{array}{l}\text { Combined treatment } \\
\text { group }(n=49)\end{array}$ & $\begin{array}{l}\text { Control group } \\
\qquad(\mathrm{n}=49)\end{array}$ & $\chi^{2} /$ t-value & P-value \\
\hline Male/female & $36 / 13$ & $34 / 15$ & 0.051 & 0.821 \\
\hline Age (years) & $59.2 \pm 10.2$ & $57.8 \pm 9.2$ & 0.957 & 0.352 \\
\hline \multicolumn{5}{|l|}{ Wound cause } \\
\hline Car accident & 21 & 18 & 0.194 & 0.65 \\
\hline Struck by falling object & 12 & 13 & & \\
\hline Electric shock & 4 & 5 & & \\
\hline Diabetic foot & 7 & 8 & & \\
\hline Varicose ulcer & 5 & 5 & & \\
\hline \multicolumn{5}{|l|}{ Wound location } \\
\hline Heel & 15 & 17 & 0.044 & 0.807 \\
\hline Top of foot & 4 & 4 & & \\
\hline Ankle & 10 & 8 & & \\
\hline Back of hand & 9 & 8 & & \\
\hline Palm & 4 & 4 & & \\
\hline Calf & 7 & 8 & & \\
\hline Wound area $\left(\mathrm{cm}^{2}\right)$ & $35.6 \pm 14.3$ & $34.8 \pm 13.2$ & 0.796 & 0.426 \\
\hline
\end{tabular}

drainage period, wounds in the two groups were rinsed daily with large amounts of saline. Additionally, a solution of rhEGF was uniformly sprayed on the wound surface in patients in the combined treatment group. During the application of VSD, an airproof seal was observed and maintained, and the liquid level inside the drainage bottle was observed regularly. If the drainage tube was blocked, heparin water was injected into the drainage tube to flush it through. The VSD process was carried out for 14 days in both groups, following which the status of healing was evaluated.

Observed indicators. Formation of granulation tissue on the wound surface was observed and scored within 1 month after treatment started. The formation was rated good and assigned a score of 3 points if the granulation tissue covered $95 \%$ of the wound area, was bright red and appeared fine-grained, and bled easily when touched. The formation was rated fairly good and assigned a score of 2 points if the granulation tissue covered 50-95\% of the wound area, was bright red, and appeared to bleed when touched. The formation was assigned a score of 1 point if the granulation tissue covered less than $50 \%$ of the wound area, and did not appear to bleed when touched. The wound healing rate was calculated after 1 week of treatment. Wound healing rate $(\%)=$ (original wound area - non-healing wound area) $\div$ original wound area $\times 100 \%$. The time of complete healing and epithelialization time were also recorded. The former was the time period from beginning of treatment to the time when the wound healed completely. The latter was the time period from beginning of treatment to the time when epithelialization began to appear on the wound surface. Changes in the levels of inflammatory factor were monitored. Upper limb venous blood $(5 \mathrm{ml})$ was drawn while fasting in the morning on the day before treatment began and on the following day after two weeks of continuous treatment. The serum levels of IL-6, IL-2, and TNF- $\alpha$ were measured using a double-antibody sandwich enzyme-linked immunosorbent assay. The kit was from Shanghai Beyotime Biotechnology Inc. (Shanghai, China).

Statistical analysis. Data were processed and analyzed using SPSS 20.0 statistical software (IBM SPSS, Armonk, NY, USA). Numerical data are expressed as mean \pm standard deviation. Intergroup comparisons were by t-test, and paired t-test was used for intragroup comparisons before and after treatment. Categorical data are expressed as percentage (\%). A Chi-square test ( $\chi^{2}$ test) was used for comparisons between groups. Wound healing was analyzed using a log-rank test. Differences were considered statistically significant when $\mathrm{p}<0.05$.

\section{Results}

General data of patients. Patient age, sex ratio, and wound area were comparable between the two groups, and the differences were not statistically significant ( $>0.05$ ) (Table I). No patients withdrew from the study in either group during the entire treatment process, and there were no patients lost to follow-up because of adverse events. The follow-up rate while in hospital and 12 weeks after treatment reached $100 \%$.

Formation of granulation tissue. The formation of granulation tissue in the two groups was mostly similar before treatment, and there was no significant difference between the two groups ( $p>0.05$ ). Formation of granulation tissue on the wound surface was significantly improved 1 week after the start of treatment in the combined treatment group $(\mathrm{p}<0.05)$. In the control group, formation of granulation tissue was moderately improved 1 week after treatment started, and the difference 
Table II. Formation of granulation tissue 1 week after the start of treatment in both groups.

Granulation tissue formation score

\begin{tabular}{lclrrr} 
Group & $\mathrm{n}$ & Observation time & 1 point & 2 points & 3 points \\
\cline { 3 - 6 } Combined treatment & 49 & Before treatment & 26 & 21 & 26 \\
& & After treatment & Before treatment & 24 & 22 \\
Control & 49 & After treatment & 6 & 31 \\
& & & & 23 \\
\hline
\end{tabular}

Table III. Wound healing in the two groups $(n=49)$.

\begin{tabular}{|c|c|c|c|c|}
\hline Group & $\begin{array}{l}\text { Residual wound } \\
\text { area }\left(\mathrm{cm}^{2}\right)\end{array}$ & $\begin{array}{l}\text { Wound healing } \\
\text { rate }(\%)\end{array}$ & $\begin{array}{l}\text { Epithelialization } \\
\text { time (days) }\end{array}$ & $\begin{array}{l}\text { Wound healing } \\
\text { time (days) }\end{array}$ \\
\hline Combined treatment & $15.32 \pm 1.46$ & $63.50 \pm 4.75$ & $3.72 \pm 1.51$ & $15.11 \pm 1.24$ \\
\hline Control & $23.10 \pm 2.24$ & $31.79 \pm 3.52$ & $5.58 \pm 1.88$ & $19.63 \pm 1.76$ \\
\hline t-test & 8.654 & 12.310 & 6.894 & 6.537 \\
\hline P-value & 0.001 & $<0.01$ & 0.023 & 0.031 \\
\hline
\end{tabular}

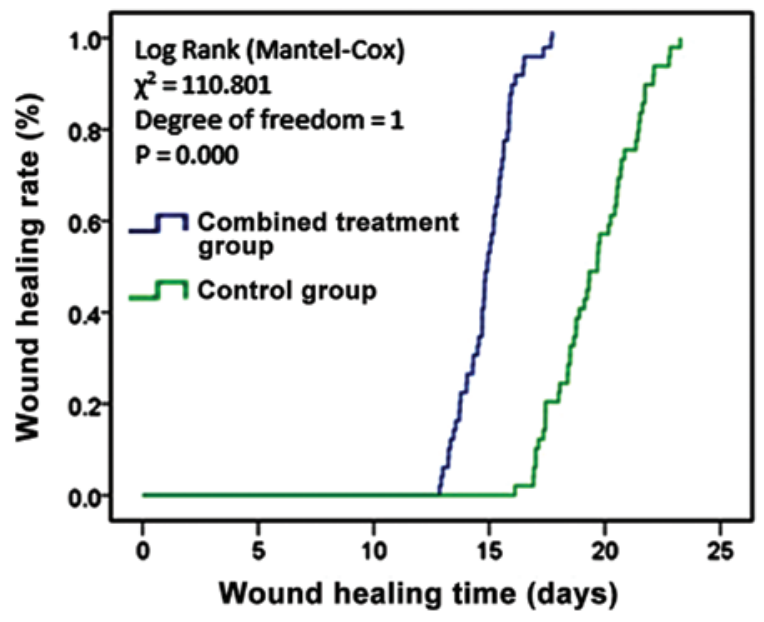

Figure 1. Wound healing in the two groups. Comparing wound healing, the wound healing time was shorter in the combined treatment group than in the control group, and the difference was statistically significant $(\mathrm{p}<0.05)$.

was statistically significant $(\mathrm{p}<0.05)$. Comparing the two groups 1 week after treatment started, formation of granulation tissue was superior in the combined treatment group compared with the control group, and the difference was statistically significant $(\mathrm{p}<0.05)$ (Table II). These results indicated that combined treatment with VSD and rhEGF was significantly effective after the first day of treatment, and wound symptoms subsided quickly.

Wound healing in the two groups. One week after treatment started, the residual wound area, wound healing rate, and time of complete healing were compared between patients in the two groups. In the combined treatment group, the parameters were $15.32 \pm 1.46 \mathrm{~cm}^{2}, 63.50 \pm 4.75 \%$, and $15.11 \pm 2.24$ days, respectively. In the control group, they were $23.1 \pm 2.2 \mathrm{~cm}^{2}$,
$31.79 \pm 3.52 \%$, and $19.36 \pm 2.76$ days, respectively. The differences in the parameters between the two groups were all statistically significant $(\mathrm{p}<0.05)$ (Table III). Fig. 1 shows the comparison of wound healing in the two groups, which indicated that combined treatment with VSD and rhEGF improved the wound healing rate, and shortened the times of epithelialization and wound healing.

Changes in the levels of inflammatory factors. The serum levels of inflammatory mediators, IL-6, IL-2, and TNF- $\alpha$, were comparable before treatment in the two groups, and the differences were not statistically significant $(p>0.05)$. After treatment, the levels were significantly lower in the combined treatment group than in the control group $(\mathrm{p}<0.05)$. In another comparison, the levels of these three inflammatory mediators were lower after treatment than before treatment in both groups, and the differences were statistically significant (p<0.05) (Tables IV-VI and Fig. 2).

\section{Discussion}

Chronic refractory wounds in the extremities are quite common in clinic. These wounds do not heal for a long period of time, and their conventional treatment is mainly dressing change. Wound healing takes a long time, and if the wound does not heal, surgical skin-grafting is eventually performed to repair it $(9,10)$. Chronic ulcer wounds are often associated with chronic infection, and are resistant to multiple antibiotics, thus resulting in low survival rate of skin grafts and posing a challenge in clinical treatment.

A number of studies have shown that (11-13) VSD treatment can effectively shorten wound healing time, reduce the pain associated with wound dressing changes, and effectively avoid cross infection. VSD is performed in a closed system, and the negative pressure drainage system promptly removes 
Table IV. Serum levels of IL-6 before and after treatment in the two groups (pg/ml, n=49).

\begin{tabular}{lccr}
\hline Group & Before treatment & After treatment & t-test \\
\hline Combined treatment & $94.37 \pm 12.56$ & $48.64 \pm 8.91$ & 11.007 \\
Control & $99.62 \pm 11.36$ & $69.43 \pm 10.23$ & 8.926 \\
t-test & 2.031 & 12.237 & -001 \\
P-value & 0.452 & 0.001 & - \\
\hline
\end{tabular}

Table V. Serum levels of IL-2 before and after treatment in the two groups (pg/ml, n=49).

\begin{tabular}{lccr}
\hline Group & Before treatment & After treatment & t-test \\
\hline Combined treatment & $28.54 \pm 2.16$ & $14.95 \pm 1.69$ & 10.294 \\
Control & $26.28 \pm 2.51$ & $20.08 \pm 1.52$ & 9.045 \\
t-test & 1.835 & 9.872 & -0.001 \\
P-value & 0.420 & 0.001 & - \\
\hline
\end{tabular}

Table VI. Serum levels of TNF- $\alpha$ before and after treatment in the two groups $(n g / 1, n=49)$.

\begin{tabular}{|c|c|c|c|c|}
\hline Group & Before treatment & After treatment & t-test & P-value \\
\hline Combined treatment & $224.43 \pm 24.58$ & $80.53 \pm 14.62$ & 14.522 & 0 \\
\hline Control & $231.42 \pm 25.36$ & $121.32 \pm 22.86$ & 12.056 & 0.001 \\
\hline t-test & 1.694 & 11.695 & - & - \\
\hline P-value & 0.337 & $<0.01$ & - & - \\
\hline
\end{tabular}
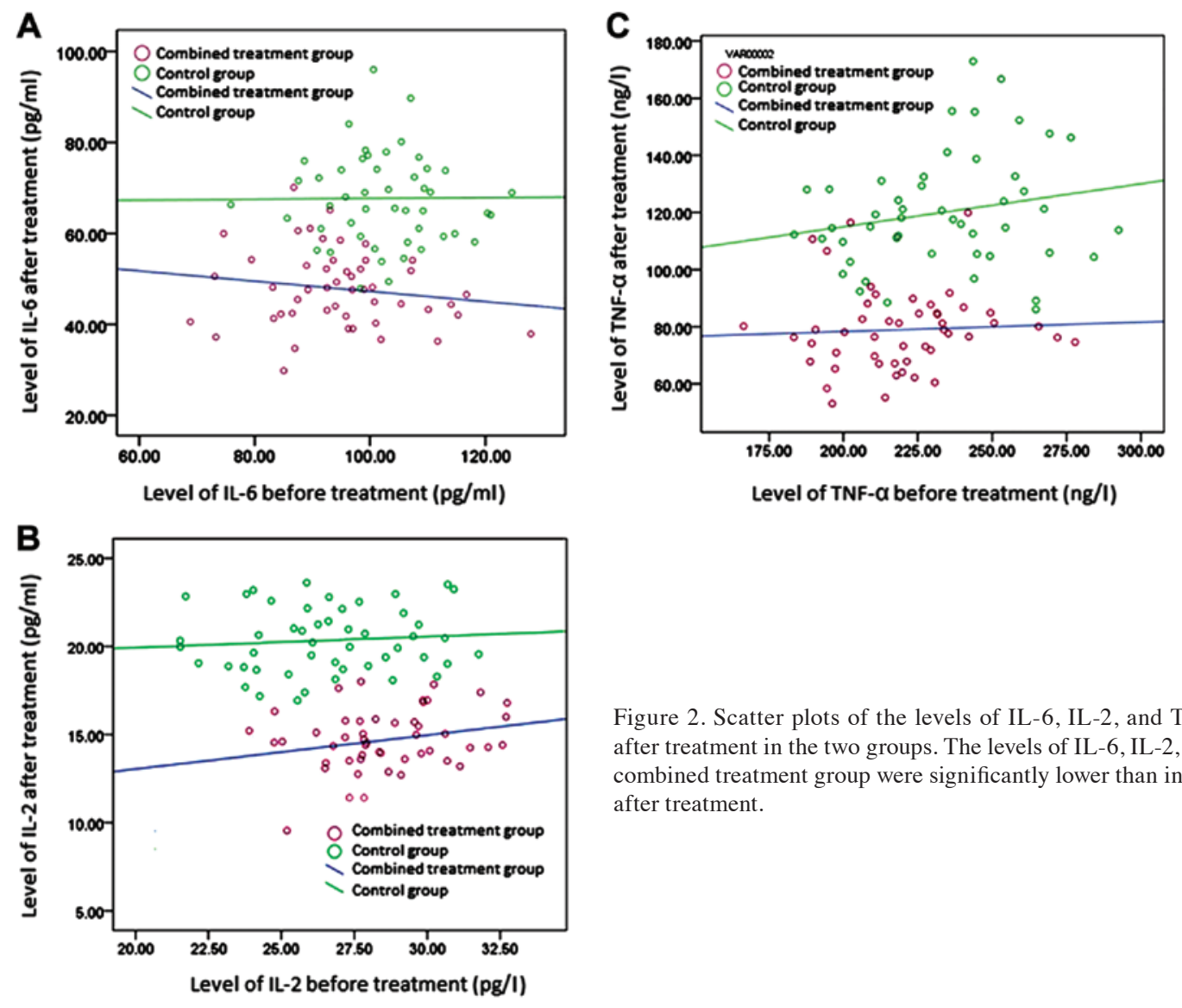

Figure 2. Scatter plots of the levels of IL-6, IL-2, and TNF- $\alpha$ before and after treatment in the two groups. The levels of IL-6, IL-2, and TNF- $\alpha$ in the combined treatment group were significantly lower than in the control group after treatment. 
any exudates and necrotic tissue to achieve zero necrotic tissue accumulation. In addition, VSD can protect the wound from contamination, stimulate the wound surface and granulation tissue for rapid and healthy growth, promote wound healing, reduce application of antibiotics, and increase blood flow in the wound surface. The continuous negative pressure can be adjusted to match physiological conditions so that it does not adversely affect blood circulation. Moreover, it can effectively prevent the formation of residual abscesses and dead space (14). More importantly, the continuous negative pressure promotes the flow of body fluid from the wound to the drainage tube, which provides an effective and sustained auxiliary power to blood circulation (15). rhEGF is the active ingredient in the rhEGF external solution which also contains $10 \%$ glycerol and $1.0 \%$ mannitol as protective agents. It can promote the synthesis of DNA, RNA, and hydroxyproline during the repair of skin and mucosal wound tissues. In addition, it can accelerate granulation tissue formation and epithelial cell proliferation, thus shortening the wound-healing time. In this study, we found that patients in the control group (treated with VSD only) had lower levels of inflammatory factors and improved granulation tissue formation score compared with before treatment $(\mathrm{p}<0.05)$.

EGF is an important growth factor synthesized in the body. It has a potent stimulatory effects on division and growth of epidermal cells. It can promote rapid proliferation of various epithelial cells to accelerate healing of surface ulcer wounds (16). Xing et al (17) reported that combined treatment with VSD and EGF for surface refractory wounds is effective, and can promote repair of damaged tissue and accelerate wound healing. Dumantepe et al (18) reported the efficacy of recombinant human EGF in the treatment of chronic diabetic foot ulcer. Its debridement efficiency for patients in the treatment group was significantly better than in the control group. In addition, it reduced the wound infection rate. Gainza et al (19) prepared rhEGF-loaded Poly-Lactic-co-Glycolic-Acid-Alginate microspheres for treatment in a Wistar rat model of diabetic skin wound. The in vivo experiments showed a significant decrease of the wound area by days 7 and 11, complete re-epithelialization by day 11 , and earlier resolution of the inflammatory process. These findings demonstrated that application of rhEGF-loaded microspheres promoted more effective wound healing. In this study, we found that combined treatment with rhEGF and VSD was effective in patients after the first day of treatment, and wound symptoms subsided quickly. In addition, combined treatment with rhEGF and VSD improved the wound-healing rate, and shortened the epithelialization and wound-healing times. These findings indicated that the effect of rhEGF on promoting epidermal cell growth was enhanced under the continuous negative pressure of VSD treatment because of improved blood circulation and decreased inflammation.

Patients with refractory wounds experience strong local inflammatory responses, demonstrated by elevated levels of inflammatory mediators such as IL-6, IL-2, and TNF- $\alpha$ (20). Nasole et al (20) reported that IL-6 and TNF- $\alpha$ are key mediators of general inflammation, which directly and indirectly induce the production of other cytokines and growth factors that affect endothelial and fibroblast function. IL-6 was confirmed to be necessary for epithelial formation because of its role in granulation tissue formation, as demonstrated by delayed wound healing process in IL-6 knockout mice (21). With the healing of local wounds, local inflammation was rapidly reduced, and the levels of inflammatory factors returned to normal, resulting in decreased decomposition of wound tissue protein and promotion of wound healing (22). In this study, the combined treatment was demonstrated to be more effective than the control treatment in reducing the levels of inflammatory factors.

In conclusion, combined treatment with VSD and rhEGF contributed to shortened healing time of refractory wounds in the extremities, and decreased inflammatory response on the wound surface. Measurement of related inflammatory factors provided a reference for prognostic assessment of refractory wounds, which merits clinical promotion.

\section{References}

1. Game FL, Attinger C, Hartemann A, Hinchliffe RJ, Löndahl M, Price PE and Jeffcoate WJ; International Working Group on the Diabetic Foot: IWGDF guidance on use of interventions to enhance the healing of chronic ulcers of the foot in diabetes. Diabetes Metab Res Rev 32 (Suppl 1): 75-83, 2016.

2. Kim H, Kong WH, Seong KY, Sung DK, Jeong H, Kim JK, Yang SY and Hahn SK: Hyaluronate-epidermal growth factor conjugate for skin wound healing and regeneration. Biomacromolecules 17: 3694-3705, 2016.

3. Suh H, Lee AY, Park EJ and Hong JP: Negative pressure wound therapy on closed surgical wounds with dead space: Animal study using a swine model. Ann Plast Surg 76: 717-722, 2016

4. Poon H, Le Cocq H, Mountain AJ and Sargeant ID: Dermal fenestration with negative pressure wound therapy: A technique for managing soft tissue injuries associated with high-energy complex foot fractures. J Foot Ankle Surg 55: 161-165, 2016.

5. Memon AA, Sundquist K, Ahmad A, Wang X, Hedelius A and Sundquist J: Role of IL-8, CRP and epidermal growth factor in depression and anxiety patients treated with mindfulness-based therapy or cognitive behavioral therapy in primary health care. Psychiatry Res 254: 311-316, 2017.

6. Guo XF, Zhu XF, Cao HY, Zhong GS, Li L, Deng BG, Chen P, Wang PZ, Miao QF and Zhen YS: A bispecific enediyneenergized fusion protein targeting both epidermal growth factor receptor and insulin-like growth factor 1 receptor showing enhanced antitumor efficacy against non-small cell lung cancer. Oncotarget 8: 27286-27299, 2017.

7. Gomez-Villa R, Aguilar-Rebolledo F, Lozano-Platonoff A, Teran-Soto JM, Fabian-Victoriano MR, Kresch-Tronik NS, Garrido-Espíndola X, Garcia-Solis A, Bondani-Guasti A, Bierzwinsky-Sneider G, et al: Efficacy of intralesional recombinant human epidermal growth factor in diabetic foot ulcers in Mexican patients: A randomized double-blinded controlled trial. Wound Repair Regen 22: 497-503, 2014.

8. Singla S, Garg R, Kumar A and Gill C: Efficacy of topical application of beta urogastrone (recombinant human epidermal growth factor) in Wagner's Grade 1 and 2 diabetic foot ulcers: Comparative analysis of 50 patients. J Nat Sci Biol Med 5: 273-277, 2014.

9. Wu W, Zeng LN, Peng YY, Lu XH, Li CY and Wang ZC: The effects of recombinant human epithelialgrowth factor and protein-free calf blood extract for recovery of corneal mechanical epithelial defects healing and neovascularization. Eur Rev Med Pharmacol Sci 18: 3406-3411, 2014.

10. Shin JU, Kang SW, Jeong JJ, Nam KH, Chung WY and Lee JH: Effect of recombinant human epidermal growth factor on cutaneous scar quality in thyroidectomy patients. J Dermatolog Treat 26: 159-164, 2015.

11. Ojalvo AG, Acosta JB, Marí YM, Mayola MF, Pérez CV, Gutiérrez WS, Marichal II, Seijas EÁ, Kautzman AM, Pacheco AE, et al: Healing enhancement of diabetic wounds by locally infiltrated epidermal growth factor is associated with systemic oxidative stress reduction. Int Wound J 14: 214-225, 2017.

12. Yang F, Shi B and Cao L: Effect of vacuum sealing drainage on the expression of VEGF and miRNA-17-5p in seawater-immersed blast-injury wounds. Exp Ther Med 13: 1081-1086, 2017. 
13. Braun LR, Fisk WA, Lev-Tov H, Kirsner RS and Isseroff RR Diabetic foot ulcer: An evidence-based treatment update. Am J Clin Dermatol 15: 267-281, 2014.

14. Ertugrul BM, Lipsky BA and Guvenc U; Turkish Intralesional Epidermal Growth Factor Study Group for Diabetic Foot Wounds: An assessment of intralesional epidermal growth factor for treating diabetic foot wounds the first experiences in Turkey. J Am Podiatr Med Assoc 107: 17-29, 2017.

15. Cheng HT, Hsu YC and Wu CI: Efficacy and safety of negative pressure wound therapy for Szilagyi grade III peripheral vascular graft infection. Interact Cardiovasc Thorac Surg 19: 1048-1052, 2014.

16. Novak A, Khan WS and Palmer J: The evidence-based principles of negative pressure wound therapy in trauma and orthopedics. Open Orthop J 8: 168-177, 2014.

17. Xing B, Wu F, Li T, Qi S, Xie J and Ye Z: Experimental study of comparing rhEGF with $\mathrm{rh} \beta \mathrm{FGF}$ on improving the quality of wound healing. Int J Clin Exp Med 6: 655-661, 2013.

18. Dumantepe M, Fazliogullari O, Seren M, Uyar I and Basar F: Efficacy of intralesional recombinant human epidermal growth factor in chronic diabetic foot ulcers. Growth Factors 33: 128-132, 2015.

19. Gainza G, Aguirre JJ, Pedraz JL, Hernández RM and Igartua M rhEGF-loaded PLGA-Alginate microspheres enhance the healing of full-thickness excisional wounds in diabetised Wistar rats. Eur J Pharm Sci 50: 243-252, 2013.

20. Nasole E, Nicoletti C, Yang ZJ, Girelli A, Rubini A, Giuffreda F, Di Tano A, Camporesi E and Bosco G: Effects of alpha lipoic acid and its R+ enantiomer supplemented to hyperbaric oxygen therapy on interleukin-6, TNF- $\alpha$ and EGF production in chronic leg wound healing. J Enzyme Inhib Med Chem 29: 297-302, 2014.
21. Rozenblum N, Zeira E, Bulvik B, Gourevitch S, Yotvat H, Galun E and Goldberg SN: Radiofrequency ablation: inflammatory changes in the periablative zone can induce global organ effects, including liver regeneration. Radiology 276: 416-425, 2015.

22. Okada Y, Shirai K, Reinach PS, Kitano-Izutani A, Miyajima M, Flanders KC, Jester JV, Tominaga M and Saika S: TRPA1 is required for TGF- $\beta$ signaling and its loss blocks inflammatory fibrosis in mouse corneal stroma. Lab Invest 94: 1030-1041, 2014.

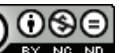

This work is licensed under a Creative Commons Attribution-NonCommercial-NoDerivatives 4.0 International (CC BY-NC-ND 4.0) License. 